College Alcohol Belief and Alcohol Use:

Testing Moderations by Cultural Orientations and Ethnicity

P. Priscilla Lui and Shalanda R. Berkley

Southern Methodist University

Byron L. Zamboanga

Smith College

Author note: P. Priscilla Lui and Shalanda R. Berkley, Department of Psychology, Southern Methodist University; Byron L. Zamboanga, Department of Psychology, Smith College. The authors would like to acknowledge Kathryn Curtis and Susie Kim for their assistance in data collection. Findings from this study have been presented as a paper presentation entitled, "Ethnic differences in the roles of college alcohol salience in hazardous alcohol use" at the $28^{\text {th }}$ Annual Texas Research Society on Alcoholism Scientific Meeting, and as a poster entitled, "Impact of college alcohol salience on drinking: Moderations by acculturation" at the $5^{\text {th }}$ Biennial convention of the Society for Psychological Study of Culture, Ethnicity, and Race. Correspondence should be directed to P. Priscilla Lui, Phone: 214-768-3679, Fax: 214-768-1041, Email: plui@smu.edu, Mail: PO Box 750442, Dallas TX 75275-0442.

(C)American Psychological Association, 2019. This paper is not the copy of record and may not exactly replicate the authoritative document published in the APA journal. Please do not copy or cite without author's permission. 


\begin{abstract}
Alcohol is considered an integral part of the college life; students who hold stronger college alcohol beliefs typically consume more alcohol and experience more negative drinking consequences. Asian Americans are increasingly at risk for hazardous alcohol use, yet little research has focused on whether college alcohol beliefs are conceptualized similarly in this group and whether individuals' cultural orientations moderate the relations between college alcohol beliefs and alcohol involvement. Asian American $\left(N=439 ; M_{\text {age }}=22.77,42.6 \%\right.$ women) and Euro American $\left(N=161 ; M_{\text {age }}=21.04 ; 41.6 \%\right.$ women $)$ undergraduate students were recruited to test measurement invariance of the College Life Alcohol Salience Scale (CLASS) and the Stephenson Multigroup Acculturation Scale (SMAS). We examined the relations between college alcohol beliefs and alcohol involvement, and the degree to which cultural orientations and ethnicity moderated these relations. Scores from a 14-item CLASS and a 26-item SMAS demonstrated scalar invariance across Asian and Euro American groups. Bivariate correlations showed robust associations between college alcohol beliefs and alcohol involvement. Among Asian and Euro Americans who were not immersed in their ethnic heritage society, students were at greater odds of being a drinker when they endorsed stronger college alcohol beliefs, and drinkers consumed more alcohol when they endorsed lower college alcohol beliefs. Interventions aimed to prevent alcohol use and misuse can assess and target students' college alcohol beliefs and promote greater connectedness to their ethnic heritage cultures.
\end{abstract}

Keywords: acculturation; beliefs; cognition; enculturation; social norms;

Public Significance Statement: Although beliefs that alcohol plays an integral part in college experiences are associated with greater alcohol consumption, individuals who are less immersed in their ethnic heritage cultures are more likely to be drinkers and are predisposed to greater alcohol consumption. This study highlights the importance of considering both cultural factors and individual differences in cognitions that underlie alcohol involvement in both Euro and Asian American groups. 


\section{College Alcohol Belief and Alcohol Use: \\ Testing Moderations by Cultural Orientations and Ethnicity}

College years mark a critical transitional period for emerging adults. Living away from home, enhanced independence from parental supervision, and increased influences from peers have been shown to be linked to greater behavioral and mental health concerns among college students (Carter, Brandon, \& Goldman, 2010). Consistent with data showing greater per capita alcohol consumption among individuals in the U.S. than in Asian and African countries (WHO, 2016), about $40 \%$ college students engage in binge and heavy drinking in Western countries including the U.S. (Dantzer, Wardle, Fuller, Pampalone, \& Steptoe, 2006). In the U.S., there are also ethnic differences in rates of alcohol use and misuse, and drinking-related problems (SAMHSA, 2017): Euro Americans are the most likely to consume alcohol and are at greatest risk for being diagnosed with alcohol use disorder (Grant et al., 2015). Despite relatively lower levels of hazardous alcohol use than Euro Americans and other ethnic groups, Asian Americans have seen greater and continued increases in alcohol use behaviors from 1993 to 1997, and 20012002 to 2012-2013 (Grant et al., 2017, SAMHSA, 2017; Wechsler, Dowdall, Maenner, GledhillHoyt, \& Lee, 1998). These ethnic differences in alcohol involvement can be explained by individual difference factors such as alcohol-related beliefs (Osberg et al., 2010) and contextual factors related to cultural orientations and drinking cultures (Tan, 2012; Todorova et al., 2013). Understanding these risks in alcohol (mis)use is an important step toward identifying active ingredients in alcohol interventions, and reducing and preventing problematic college drinking. The goals of this study were to examine college alcohol beliefs and cultural orientations as determinants of alcohol involvement among Asian and Euro Americans.

\section{College Alcohol Beliefs}


Ethnic differences in alcohol use have been found to be fully accounted for by drinkingrelated beliefs such as perceived norms and alcohol expectancies (Antin, Lipperman-Kreda, Paschall, Marzell, \& Battle, 2014). National cultures and U.S. ethnic groups vary in social norms pertaining to "when, where, why, and how people drink, how much they drink, their expectations about the effects of different amounts of alcohol, and the behaviours they engage in before, during, and after drinking" (Savic et al., 2016, p. 280). Consuming alcohol frequently is considered an integral part of college life, and these college alcohol beliefs are embedded within a permissive U.S. drinking culture (Tan, 2012). Characteristics of campus environments (e.g., presence of Greek communities, availability of alcohol in parties) can reinforce college alcohol beliefs and in turn promote alcohol consumption and increase drinking-related problems among college students (Borsari, Murphy, \& Barnett, 2007; Carter et al., 2010; Mallett et al., 2013). Additionally, media and peer influences can increase the likelihood that college students internalize more permissive and favorable attitudes toward drinking (Borsari \& Carey, 2001; Gibbons et al., 2010).

These college alcohol beliefs tend to include expectations of abundant availability of alcohol at parties and the notion that alcohol involvement is typical and an integral aspect of the college experience (Osberg et al., 2010). For example, many college events are accompanied by high-risk drinking activities (e.g., drinking games, prepartying; Hummer, Napper, Ehret, \& LaBrie, 2013; Zamboanga et al., 2014). Shared attitudes and beliefs about alcohol use in college can help students construct group identity and form social connections (Tan, 2012), such as those in the Greek community (Neighbors et al., 2010; Reed et al., 2007).

College alcohol beliefs, measured by the College Life Alcohol Salience Scale (CLASS), have been shown to be related to drinking motives and behaviors concurrently and prospectively 
(Osberg et al., 2010, 2011). College alcohol beliefs not only predict alcohol consumption and drinking problems above and beyond personality, but also can intensify the relations between personality vulnerability and drinking outcomes (LaBrie, Kenney, Napper, \& Miller, 2014). Overall, students who believe that heavy alcohol use is a rite of passage in college are more likely to accept and engage in hazardous alcohol use (Crawford \& Novak, 2006, 2010; Wolburg 2001). Most existing studies that examined the impact of college alcohol beliefs on alcohol involvement have included predominantly Euro Americans, however. One recent study has investigated psychometric properties of the CLASS scores across sociodemographic groups (Lui, 2019) and found noninvariant scale functioning across ethnic groups. Thus, it remains unclear whether there are similar roles of college alcohol beliefs on alcohol involvement across individuals of non-Euro American backgrounds and different cultural orientations. Particularly, the model minority stereotype about Asian Americans has continued to underestimate their highrisk drinking behaviors and impeded advancement in alcohol research in this population (Cheng, Iwamoto, \& McMullen, 2018; Iwamoto, Le, Brady, \& Kaya, 2018). With increasing levels of alcohol (mis)use among Asian Americans, how individuals conceptualize and relate to the mainstream American and ethnic (drinking) cultures likely are important in illuminating alcohol involvement in this population.

\section{Cultural Orientations and Alcohol Use Outcomes}

Many individuals, particularly those from ethnic minority or immigrant backgrounds, are tasked with having to navigate the norms and expectations from their ethnic heritage culture and the mainstream U.S. culture to best adapt to their environment (Berry, 2005). Individuals may be socialized on alcohol-related beliefs as well as specific drinking norms from either the mainstream U.S. or their ethnic heritage societies (Barsties et al., 2017). Consistent with a social 
norms framework, more U.S.-oriented individuals are more likely to adhere to the more liberal and favorable alcohol beliefs, and in turn engage in greater alcohol consumption and/or experience more drinking problems than their peers who are less U.S. oriented. (Lorenzo-Blanco et al., 2016; Vaeth, Wang-Schweig, \& Caetano, 2017). The greater the distance between individuals' heritage culture and the mainstream host culture, the more likely they need to make psychological adjustments and cultural adaptations (Lui, 2015). For example, heritage European cultures (e.g., Italian) share similar drinking norms as the U.S. culture; thus, Euro Americans may be less likely to have to navigate drastically different cultural socializations about their drinking behaviors.

Research syntheses have shown small correlations between cultural orientations and alcohol use among Asian Americans (Lui \& Zamboanga, 2018). Specifically, alcohol consumption and drinking problems are positively associated with the mainstream U.S. orientation, but are either negatively or not associated with the heritage orientation. Although broad levels of U.S. ethnic heritage immersion are not strong predictors of drinking outcomes, cultural orientations likely modify the associations between college alcohol beliefs and alcohol use. This is likely particularly true for Asian Americans because of larger differences between the "American" drinking culture and Asian ethnic drinking culture. Thus, cultural orientations may be more closely related to drinking outcomes for Asian Americans than Euro Americans. Greater ethnic cultural assets (e.g., nonacceptance of heavy drinking, parental monitoring, and efficacy to resist peer pressures; Iwamoto, Kaya, Grivel, \& Clinton, 2016, Lorenzo-Blanco et al., 2016) may buffer the influence of college alcohol beliefs on alcohol involvement. Given the increasing prevalence of alcohol use disorder among Asian Americans (Grant et al., 2017), examining independent and interactive roles of college alcohol beliefs and cultural orientations 
on drinking outcomes can shed light on important universal and culturally distinct risk factors, and inform clinical interventions. We hypothesized that:

1. college alcohol beliefs would be positively associated with drinker status, alcohol consumption, and alcohol-related problems among Asian and Euro Americans;

2. these relations would be intensified by the mainstream U.S. orientation and buffered by ethnic heritage orientation (see Supplemental Figure 1); and,

3. the relations between college alcohol beliefs x cultural orientations and alcohol involvement would be stronger among Asian Americans than Euro Americans (see Supplemental Figure 2).

\section{Method}

\section{Participants and Procedures}

Domestic, non-international Asian American $\left(N=439, M_{\text {age }}=22.77,42.6 \%\right.$ women, $0.5 \%$ nonbinary $/$ transgender $\left.^{1}\right)$ and Euro American $\left(N=161, M_{\text {age }}=21.04,41.6 \%\right.$ women $)$ undergraduate students were recruited via student-directed mass emails at a predominantly White private university in the Southwest. Most Asian Americans (62.2\%) were first-generation immigrants $\left(M_{\text {age arrival }}=5.7\right)$ whereas most Euro Americans were native-born individuals of third or more immigration generation $(84.4 \%)$. The study was approved by the university's Institutional Review Board. Participants provided consent prior to completing online survey questionnaires. The study took about 60 minutes and participants received cash compensation.

\section{Measures}

College Life Alcohol Salience Scale (CLASS; Osberg et al., 2010). The CLASS is a 15item scale of beliefs on the role of alcohol in college experience. Items such as "a college party is

\footnotetext{
${ }^{1}$ Given the small number of nonbinary/transgender individuals, these two participants were removed from the analyses where gender was included as a covariate.
} 
not a true college party without alcohol" were rated from 1 (strongly disagree) to 5 (strongly agree). Initial scale development and subsequent validation data supported a single-factor structure underlying the CLASS scores, as well as construct validity in relation to drinking motives and criterion-related validity in relation to alcohol consumption and drinking problems (Lui, 2019; Osberg et al., 2010). The CLASS has shown scalar invariance across gender, years in college, and campus residence, but only partial scalar invariance across ethnic groups (Lui, 2019). Negatively worded items were reverse-coded; higher mean scale scores indicated stronger beliefs that alcohol was central to the college experience. The present 15-item CLASS scores demonstrated excellent internal consistency reliability (Cronbach's $\alpha=.92$ and .91 for Euro and Asian Americans, respectively).

Stephenson Multigroup Acculturation Scale (SMAS; Stephenson, 2000). The SMAS is a 32-item scale that measures the extent to which participants are immersed in the dominant, mainstream (Euro) American society (15 items; e.g., "I feel at home in the United States") and their ethnic heritage society (17-items; e.g., "I speak my native language with my spouse or partner"). The measure was designed to capture cultural orientations of individuals from diverse ethnic backgrounds. Items were rated from 1 (false) to 4 (true) and assessed respondents' behavioral orientations in both cultures. Negatively-worded items were reverse-coded; mean scale scores indicated higher levels of U.S. and heritage orientations, respectively. The SMAS has shown adequate internal consistency reliability and been used with Asian and Euro American samples in previous research (Levinson \& Rodebaugh, 2013; see Huynh, Howell, \& BenetMartinez, 2009 for meta-analytic review). Current mean scores with Asian and Euro Americans showed excellent to adequate internal consistency for dominant society immersion (Cronbach's $\alpha$ $=.86$ and .82 ) and ethnic society immersion (Cronbach's $\alpha=.92$ and .95 ), respectively. 
Alcohol Use Disorders Identification Test (AUDIT; Saunders et al., 1993). The first item on the AUDIT assesses frequency in which respondents consumed alcohol over the past six months. Three items assess the typical intensity of alcohol consumption (AUDIT-C) and seven items assess the severity of alcohol-related problems experienced in the past six months. Items were rated from 0 (never/1 or 2 drinks/no) to 4 (four or more times a week/10 or more drinks/daily or almost daily/yes, during the last half year). Developed by the World Health Organization, the AUDIT scales have been used as a valid screener for hazardous drinking across segments of the population (see de Meneses-Gaya, Zuardi, Loureiro, \& Crippa, 2009; Reinert \& Allen, 2002 for review). Higher summed scale scores indicated greater alcohol consumption (Cronbach's $\alpha=.87$ and .88) and alcohol-related problems (Cronbach's $\alpha=.62$ and .71) for Asian and Euro Americans, respectively. AUDIT-C scores $\geq 4$ typically is indicative of at-risk drinking (Kuitunen-Paul \& Roerecke, 2018).

\section{Data Analyses}

Analysis on measurement invariance of the CLASS and the SMAS. Previous results have shown systematic ethnic differences in item loadings and means in the CLASS (Lui, 2019). Although the SMAS was designed to be a multigroup measure of cultural orientations, no research has examined the equivalence of scale functioning across ethnicity. To ensure that college alcohol beliefs and cultural orientations were measured equivalently across our Asian and Euro American samples, we conducted a series of confirmatory factor analyses (CFAs) in Mplus v8. The CLASS data across ethnic groups were expected to show adequate fit for a singlefactor structure, whereas the SMAS data were expected to show adequate fit for a two-factor structure underlying orthogonal U.S. and heritage cultural orientations. In models conducted with maximum likelihood (ML) estimation on continuous data, an excellent fit for these factor 
structures would be indicated by $\mathrm{CFI} \geq .95, \mathrm{RMSEA} \leq .06$, and $\mathrm{SRMR} \leq .08$, whereas an adequate model fit would be indicated by $\mathrm{CFI} \geq .90, \mathrm{RMSEA} \leq .08$, and $\mathrm{SRMR} \leq .10$ (Hu \& Bentler, 1999). In models conducted with mean- and variance-adjusted weighted least squares (WLSMV) estimation on ordinal-categorical data, CFI and RMSEA were used to assess model fit. In the event that initial factor structures failed to demonstrate acceptable fit, we examined factor loadings, correlated residuals, and modification indices to identify parameter estimates that contributed to model misfit.

Replicating steps used in previous studies (Bravo et al., 2017; Lui, 2019), we tested configural (equivalent factorial pattern), metric (equivalent strength of factor loadings), and scalar (equivalent unstandardized item means/thresholds) invariance of the CLASS in multigroup CFAs. We also used the same procedures to test these invariance models for the SMAS. Metric invariance would ensure valid comparisons of correlates of college alcohol beliefs and also cultural orientations, whereas scalar invariance would ensure valid comparisons of the latent mean levels of college alcohol beliefs and cultural orientations between Asian and Euro Americans. In addition to the guidelines for standard fit indices, we examined changes in $\chi^{2}$ and CFI. $\Delta \chi^{2}$ tends to be sensitive to large sample sizes and yield statistically significant - and therefore uninformative - results. In ML-estimated models, $\Delta \mathrm{CFI} \leq-.010$ and $\triangle \mathrm{RMSEA} \leq .015$, and $\triangle \mathrm{SRMR} \leq .030$ and .015 for metric and scalar invariance, respectively, would signal that the model with more parameter constraints produced a similar fit as the model with fewer constraints, and thus demonstrating measurement invariance at each level (Chen, 2007; Cheung \& Rensvold, 2002). In WLSMV-estimated models, only $\Delta \mathrm{CFI} \leq-.010$ and $\triangle \mathrm{RMSEA} \leq .015$ would be used to evaluate measurement invariance.

Often, fit index thresholds fail to converge on measurement invariance results. Given that 
$\Delta \mathrm{CFI} \leq-.010$ has been the most frequently used criterion in psychological research (Putnick \& Bornstein, 2016), and is neither the most $(\triangle \mathrm{CFI}<-.002)$ or least restrictive $(\triangle \mathrm{RMSEA} \leq .015)$, we considered all fit indices and relied on $\Delta C F I \leq-.010$ in the event that fit indices suggested different results. Additionally, in the event that metric invariance or scalar invariance was not achieved, we identified items that contributed to the model misfit and relaxed equality constraints for those parameters to allow for partial invariance (Widaman \& Reise, 1997).

Hypothesis testing. To examine the roles of college alcohol beliefs, cultural orientations, and ethnicity in alcohol use outcomes, we conducted simultaneous regression analyses in SPSS. We computed two- and three-way interaction terms by multiplying scores of predictor variables. To test $\mathrm{H} 1$ and H2, college alcohol beliefs, U.S. and heritage orientations, and college alcohol beliefs x U.S. orientation and college alcohol beliefs x heritage orientations were entered in regression model for each alcohol use outcome (see Model 1 in Supplemental Figure 1).

Ethnicity and college alcohol beliefs x ethnicity also were included as predictor variables. To test H3, we added two three-way interaction terms (i.e., college alcohol beliefs x U.S. orientation $\mathrm{x}$ ethnicity, college alcohol beliefs x heritage orientation x ethnicity; see Model 2 in Supplemental Figure 2). Research has shown gender differences in alcohol involvement (Erol \& Karpyak, 2015) and the associations between cultural orientations and alcohol use (Lui \& Zamboanga, 2018; Zamoanga, Tomaso, \& Lui, 2017), thus gender was entered as a covariate in all analyses.

\section{Results}

\section{Measurement Invariance of the CLASS and the SMAS}

The CLASS data met assumptions for CFAs with ML estimation. The single-factor structure adequately fit the CLASS scores, $\chi^{2}(90)=251.84, \mathrm{CFI}=.94, \mathrm{RMSEA}=.07(90 \% \mathrm{CI}$ $=.06, .08), \mathrm{SRMR}=.04$ (see Supplemental Table 1 for item descriptive statistics and loadings by 
ethnicity). We found evidence for configural invariance, but not full metric invariance (see Supplemental Table 2 for summary of model fit indices). Item 3, "I would prefer it if my college was not considered a party school," did not load onto the latent factor of college alcohol beliefs among Asian Americans. Once this loading constraint was freed, we achieved partial scalar invariance. The 14-item scale scores demonstrated excellent internal consistency in both groups (Cronbach's $\alpha=.91$ and .92).

The SMAS data showed non-normal residuals, and therefore WLSMV estimator was used in CFAs. The initial two-factor structure of the 32-item SMAS did not fit the current data well. Two items, "I eat traditional foods from my country of origin culture" and "I regularly read an American newspaper" did not show salient loadings $(\leq .40)$ onto either factors in the CFA with the entire sample. According to modification indices, three items, "I feel accepted by Anglo Americans," "I am familiar with the history of my country of origin," and "I think in English" showed nontrivial cross-loadings $(\geq .20)$ that were not specified by the original factor structure. These five items were removed, and the remaining 27-item data demonstrated adequate model fit, $\chi^{2}(298)=1069.422, \mathrm{CFI}=.96, \mathrm{RMSEA}=.07(90 \% \mathrm{CI}=.07, .08), \mathrm{WRMR}=1.70$. Supplemental Table 3 shows item descriptive statistics and loadings from the best-fitting model. Upon closer examination, Item 1, “I understand English, but I'm not fluent in English” was associated with the dominant society immersion factor positively in the Euro American sample, but negatively in the Asian American sample. This item demonstrated noninvariance in item loading, thus was removed from the scale. The modified 26-item SMAS data showed configural, metric, and scalar invariance across ethnic groups (see Supplemental Table 4 for model fit indices).

\section{Ethnic Differences and Prediction of Alcohol Involvement}


As shown in the Appendix, we used group invariant CLASS and SMAS data in subsequent analyses. Descriptive statistics showed an ethnic difference in the proportion of drinkers. There were more Euro Americans (90.7\%) than Asian Americans (67.8\%) who reported having consumed alcohol in the past six months. Table 1 summarizes mean and correlational differences across ethnicity. Among drinkers, Asian and Euro Americans differed in college alcohol beliefs, alcohol use outcomes, and U.S. cultural orientation. Consistent with prior research with Asian Americans, alcohol consumption was positively associated with U.S. orientation and negatively associated with heritage orientation. Unexpectedly, alcohol-related problems were negatively correlated with U.S. orientation among Asian Americans.

Drinker status. Table 2 summarizes logistic regression results predicting drinker status. As indicated by the likelihood ratio $\chi^{2}$ tests, both Model 1 and Model 2 were statistically significant improvements over the baseline intercept-only model. Data supported H1. With one unit increase in college alcohol beliefs, individual would be 160.67 times more likely to be a drinker even after accounting for gender. This association was not moderated by ethnicity. Additionally, H2 was partially supported. Heritage cultural orientation, but not U.S. cultural orientation, moderated the association between college alcohol beliefs and drinker status. As shown in Figure 1, greater immersion in one's ethnic heritage society buffered the association between college alcohol beliefs and the probability of drinker status. Data did not support H3, however. When ethnicity was included as a moderator in Model 2, there were no statistically significant predictor variables in the regression model.

Alcohol consumption. Alcohol consumption was a count variable and scores were skewed in the current sample. Constraining data from individuals who consumed alcohol in the past six months, we examined dispersion parameter and model fit indices and found that Poisson 
distribution was a better fit than negative binomial distribution. Table 3 summarizes Poisson regression results for Model 1 and Model 2. Heritage orientation was found to be associated with lower levels of drinking; each one unit increase in ethnic immersion corresponded to a $29 \%$ decrease in incidence rate for alcohol consumption. As shown in Figure 2, there were no associations between overall amount of alcohol consumption and college alcohol beliefs. Compared to their peers who score high on heritage cultural orientation and those who believed in a central role of alcohol in college, individuals who scored low on both heritage orientation and college alcohol beliefs consumed more alcohol.

Alcohol-related problems. Data on alcohol-related problems were overdispersed, thus negative binomial regression was more appropriate than Poisson regression for this outcome variable. As indicated by the likelihood ratio $\chi^{2}$ tests, Model 1 and Model 2 both were statistically significantly better-fitting models for alcohol-related problems than the interceptonly model. Table 4 summarizes negative binomial regression results. Neither H1, H2, nor H3 were supported when gender, ethnicity, and cultural orientation, and the two-way and three-way interactions among college alcohol beliefs, cultural orientations, and ethnicity were included in the model. Both heritage and U.S. cultural orientations were uniquely and negatively associated with alcohol-related problems (see Model 1). When college alcohol beliefs x U.S. orientation x ethnicity and college alcohol beliefs $\mathrm{x}$ heritage orientation $\mathrm{x}$ ethnicity interactions were added to the regression analysis, U.S._- but not heritage — cultural orientation remained a statistically significant predictor variable. With each one unit increase in dominant society immersion, individuals would see a 54\% decrease in alcohol-related problems (see Model 2).

\section{Discussion}

Our study contributes to the literature in two ways. First, we examined the psychometric 
properties and equivalence of measures of college alcohol beliefs and cultural orientations across ethnicity. Second, we considered the interactive roles of cultural orientations and alcohol beliefs in alcohol involvement among Asian and Euro Americans. The CLASS was found to be a generally reliable and robust measure of college alcohol beliefs, and only one scale item was noninvariant across Asian and Euro Americans. Additionally, most items in the SMAS demonstrated equivalent scale functioning across ethnic groups in terms of U.S. and heritage cultural orientations. Whereas college alcohol beliefs were understood similarly across many segments of the college population for the most part (Lui, 2019), their associations with drinker status and alcohol consumption were conditional on students' heritage cultural orientation. Specifically, believing that alcohol is an integral part of the college experience is linked to greater odds of being a drinker, but the association is relatively weaker among those who are more connected to their ethnic heritage society. Among drinkers, we found a robust conditional relation linking college alcohol beliefs and heritage cultural orientation to alcohol consumption. Being disconnected from ethnic heritage society seems to heighten students' risk for alcohol consumption especially when they do not have strong beliefs about alcohol's salience in college experience.

Currently, there are no theoretical models that guide systematic conceptualization of determinants of alcohol involvement, and implementation of alcohol prevention and treatment both universally and in specific ethnocultural contexts (Bennett \& Ames, 1985). Whereas some research has criticized that cultural orientations or acculturation statuses do not satisfactorily predict and explain health behaviors such as alcohol use (Hall, Yip, \& Zarate, 2016, Lazarus, 1997), our results highlight the importance of simultaneously considering sociocultural contexts surrounding individual differences in drinking-related cognitions in both ethnic majority and 
minority groups. Although we expected that cultural orientations to not "hit home" for Euro Americans because our sample consisted of predominantly third- and fourth-generation individuals who are rather distant from their ethnic heritage cultures (e.g., Polish, Italian) and are the majority group in the dominant society, no ethnic differences in the relations between college alcohol beliefs and alcohol involvement emerge once we identify a set of ethnically invariant items on cultural orientations. The measurement invariance of the modified SMAS yields compelling evidence that dominant U.S. and ethnic heritage cultures can be identified and differentiated among Euro Americans in the same way as Asian Americans.

Accounting for the influence of U.S. orientation, heritage cultural orientation appears to be a protective factor against drinker status and alcohol consumption among college students. To the extent that many ethnic cultures provide cultural scripts on drinking practices, individuals who are more immersed in their ethnic heritage society may be socialized to abstain from drinking (especially in social contexts that are deemed inappropriate; Sue et al., 1985; Westermeyer, 1985). Although the process of acculturation can predispose individuals to greater alcohol involvement (see Vaeth et al., 2017), differentiating U.S. and heritage orientations highlights the protective roles of ethnic society immersion. The interactive effect of college alcohol beliefs and heritage cultural orientation on alcohol consumption suggests that individuals who do not regard alcohol to be important in their college experience may be drinking for reasons other than socializing and having a good time (e.g., coping with social isolation and other stresses). For example, individuals with social disadvantages (e.g., low socioeconomic status, exposure to discrimination) may engage in alcohol use as a means to alleviate stress (Cooper, Russell, Skinner, Frone, \& Mudar, 1992; Corbin, Farmer, \& Nolen-Hoekesma, 2013; Mulia \& Zemore, 2012). Ethnic minority college students who are marginalized from both 
mainstream U.S. and ethnic heritage societies consume more alcohol and exhibit more drinkingrelated problems than their peers who are immersed in either of or both societies (Pham \& Lui, 2019ab). Under these circumstances, individuals who are not immersed in their ethnic heritage society may not enjoy the benefit of specific cultural elements (e.g., family support) that protect them from hazardous alcohol use (Kim, Zane, \& Hong, 2002).

\section{Implications for Counseling Practices}

The present findings underscore the importance of prevention efforts that screen and target college students for alcohol involvement. First, the CLASS is a brief and relatively robust screening tool for alcohol beliefs among college students; administering the CLASS to assess students' college alcohol beliefs can raise awareness and provide individualized feedback in prevention and intervention programs (Lui, 2019). Challenging favorable college alcohol belief very early on in college, such as de-emphasizing the integral role of alcohol on campus and promoting other important aspects of the college experience (e.g., academic achievement and sense of community; Toomey \& Wagenaar, 2002), may be a viable means to prevent hazardous drinking (Cooper, 1999). Above and beyond drinking-related beliefs, promoting college students' knowledge of and emotional connection to their ethnic heritage culture can lower their risk for engaging in alcohol use and reduce the amount of consumption. Fostering a strong sense of heritage orientation may help college students build social networks for support and develop ethnic pride (Cook, Mulia, \& Karriker-Jaffe, 2012).

\section{Limitations and Future Directions}

The present findings should be contextualized with the following limitations in mind. First, whereas we used a cross-sectional dataset to examine the associations between alcohol beliefs and alcohol involvement, it is important to recognize that alcohol beliefs are complex 
(Savic et al., 2016) and can change over time. Asian American students who negotiate their cultural identities throughout college may experience changes in their cultural orientations and alcohol-related beliefs over time. Second, we did not have sufficient power to disentangle subgroup differences across Asian and European heritage backgrounds. Heritage cultural orientation is a broad representation of people's internal working models about the norms and values from their countries of origin. It is possible that the use of ethnically heterogeneous samples of Asian and Euro Americans undermines the associations between heritage cultural orientations and alcohol use in specific ethnic subgroups. Thus, research examining how cultural orientation is associated with alcohol involvement should consider examining specific drinkingrelated cultural elements in individuals' ethnic heritage society. This would require the development of new measures of ethnic and mainstream U.S. drinking cultures in the future. Additionally, college students who leave their households of origin and ethnic communities to attend a predominantly Euro American institution may see shifts in how they conceive their heritage cultural orientation. They may be more likely to identify as "Asian" Americans rather than by their countries of origin such as "Korean" or "Indian" Americans. More research should examine identity changes over time as college students navigate intercultural adjustment. Third, studies have shown gender differences in beliefs about alcohol use and drinking patterns in the U.S. and other countries (Wilsnack, Vogeltanz, Wilsnack, \& Harris, 2000), and associations between alcohol involvement and individual attributes, and sociocultural factors. Follow-up research should examine how college alcohol beliefs, cultural orientations, ethnicity, and gender may interaction with each other to influence alcohol use among undergraduate students. 


\section{References}

Antin, T., Lipperman-Kreda, S., Paschall, M. J., Marzell, M., \& Battle, R. (2014). The role of drinking beliefs to explain ethnic variation in drinking practices among U.S. college students. Substance Use \& Misuse, 49, 95-102. doi:10.3109/10826084.2013.821659

Barsties, L. S., Walsh, S. D., Huijts, T., Bendtsen, P., Molcho, M., Buijs, T., ... \& Stevens, G. W. J. M. (2017). Alcohol consumption among first- and second-generation immigrant and native adolescents in 23 countries: Testing the importance of origin and receiving country alcohol prevalence rates. Drug and Alcohol Review, 36, 769-778. doi:10.1111/dar.12624

Bennett, L. A., \& Ames, G. M. (1985). Alcohol belief systems in a culturally pluralistic society: An introduction. In L. A. Bennett \& G. M. Ames (Eds.), The American experience with alcohol: Contrasting cultural perspectives (pp. 3-6). New York: Plenum Press.

Berry, J. W. (2005). Acculturation: Living successfully in two cultures. International Journal of Intercultural Relations, 29, 667-712. doi:10.1016/j.ijintrel.2005.07.013

Borsari, B., \& Carey, K. B. (2001). Peer influences on college drinking: A review of the research. Journal of Substance Abuse, 13, 391-424. doi:10.1016/S0899-3289(01)00098-0

Borsari, B., Murphy, J. G., \& Barnett, N. P. (2007). Predictors of alcohol use during the first year of college: Implications for prevention. Addictive Behaviors, 32, 2062-2086. doi:10.1016/j.addbeh.2007.01.017

Bravo, A. J., Pearson, M. R., Pilatti, A., Read, J. P., Mezquita, L., Ibáñez, M. I., \& Ortet, G. (2017). Cross-cultural examination of college drinking culture in Spain, Argentina, and USA: Measurement invariance testing of the College Life Alcohol Salience Scale. Drug and Alcohol Dependence, 180, 349-355. doi: 10.1016/j.drugalcdep.2017.08.016

Carter, A. C., Brandon, K. O., \& Goldman, M. S. (2010). The college and noncollege 
experience: A review of the factors that influence drinking behavior in young adulthood. Journal of Studies on Alcohol and Drugs, 71, 742-750. doi:10.15288/jsad.2010.71.742

Chen, F. F. (2007). Sensitivity of goodness of fit indexes to lack of measurement invariance. Structural Equation Modeling, 14, 464-504. doi:10.1080/10705510701301834

Cheng, A. W., Iwamoto, D. K., \& McMullen, D. (2018). Model minority stereotype and the diagnosis of alcohol use disorders: Implications for practitioners working with Asian Americans. Journal of Ethnicity in Substance Abuse, 17, 255-272. doi:10.1080/15332640.2016.1175990

Cheung, G. W., \& Rensvold, R. B. (2002). Evaluating goodness-of-fit indexes for testing measurement invariance. Structural Equation Modeling, 9, 233-255. doi:10.1207/S15328007SEM0902_5

Cook, W. K., Mulia, N., \& Karriker-Jaffe, K. (2012). Ethnic drinking cultures and alcohol use among Asian American adults: Findings from a national survey. Alcohol and Alcoholism, $47,340-348$.

Cooper, M. L., Russell, M., Skinner, J. B., Frone, M. R., \& Mudar, P. (1992). Stress and alcohol use: Moderating effects of gender, coping, and alcohol expectancies. Journal of Abnormal Psychology, 101, 139-152. doi:10.1037/0021-843X.101.1.139

Cooper, S. E. (1999). Changing the campus drinking culture: An initiator-catalyst consultation approach. Consulting Psychology Journal: Practice and Research, 51, 160-169. doi:10.1037/1061-4087.51.3.160

Corbin, W. R., Farmer, N. M., \& Nolen-Hoekesma, S. (2013). Relations among stress, coping strategies, coping motives, alcohol consumption and related problems: A mediated moderation model. Addictive Behaviors, 38, 1912-1919. 
doi:10.1016/j.addbeh.2012.12.005

Crawford, L. A., \& Novak, K. B. (2006). Alcohol abuse as a rite of passage: The effect of beliefs about alcohol and the college experience on undergraduates' drinking behaviors. Journal of Drug Education, 36, 193-212. doi:10.2190/F0X7-H765-6221-G742

Crawford, L. A., \& Novak, K. B. (2010). Beliefs about alcohol and the college experience as moderators of the effects of perceived drinking norms on student alcohol use. Journal of Alcohol and Drug Education, 54, 69-86.

Dantzer, C, Wardle, J., Fuller, R. Pampalone, Z. S. \& Steptoe, A. (2006). International Study of Heavy Drinking: Attitudes and sociodemographic factors in university students. Journal of American College Health, 55, 83-89. doi:10.3200/JACH.55.2.83-90.

de Meneses-Gaya, C., Zuardi, A. W., Loureiro, S. R., \& Crippa, J. A. S. (2009). Alcohol Use Disorders Identification Test (AUDIT): An updated systematic review of psychometric properties. Psychology \& Neuroscience, 2, 83-97. doi:10.3922/j.psns.2009.1.12

Erol, A., \& Karpyak, V. M. (2015). Sex and gender-related differences in alcohol use and its consequences: Contemporary knowledge and future research considerations. Drug and Alcohol Dependence, 156, 1-13. doi:10.1016/j.drugalcdep.2015.08.023

Gibbons, F. X., Pomery, E. A., Gerrard, M., Sargent, J. D., Weng, C.-Y., Wills, T. A., ... \& Yeh, H.-C. (2010). Media as social influence: Racial differences in the effects of peers and media on adolescent alcohol cognitions and consumption. Psychology of Addictive Behaviors, 24, 649-659. doi:10.1037/a0020768

Grant, B. F., Chou, S., Saha, T. D., Pickering, R. P., Kerridge, B. T., Ruan, W. J., ... \& Hasin, D. S. (2017). Prevalence of 12-month alcohol use, high-risk drinking, and DSM-IV alcohol use disorder in the United States, 2001-2002 to 2012-2013: Results from the National 
Epidemiologic Survey on Alcohol and Related Conditions. JAMA Psychiatry, 74, 911923. doi:10.1001/jamapsychiatry.2017.2161

Grant, B. F., Goldstein, R. B., Saha, T. D., Chou, S. P., Jung, J., Zhang, H., ... \& Hasin, D. S. (2015). Epidemiology of DSM-5 alcohol use disorder: Results from the National Epidemiologic Survey on Alcohol and Related Conditions III. JAMA Psychiatry, 72, 757-766. doi:10.1001/jamapsychiatry.2015.0584

Hall, G. C. N., Yip, T., \& Zárate, M. A. (2016). On becoming multicultural in a monocultural research world: A conceptual approach to studying ethnocultural diversity. American Psychologist, 71, 40-51. doi:10.1037/a0039734

Hu, L.-t., \& Bentler, P. M. (1999). Cutoff criteria for fit indexes in covariance structure analysis: Conventional criteria versus new alternatives. Structural Equation Modeling, 6, 1-55. doi:10.1080/10705519909540118

Hummer, J. F., Napper, L. E., Ehret, P. E., \& LaBrie, J. W. (2013). Event-specific risk and ecological factors associated with prepartying among heavier drinking college students. Addictive Behaviors, 38, 1620-1628. doi:10.1016/j.addbeh.2012.09.014

Huynh, Q.-L., Howell, R. T., \& Benet-Martínez, V. (2009). Reliability of bidimensional acculturation scores: A meta-analysis. Journal of Cross-Cultural Psychology, 40, 256274. doi:10.1177/0022022108328919

Iwamoto, D., Le, T., Brady, J., \& Kaya, A. (2018). Distinct classes of alcohol use and related problems among Asian American young adults. American Journal of Orthopsychiatry. Advance online publication.

Iwamoto, D. K., Kaya, A., Grivel, M., \& Clinton, L. (2016). Under-researched demographics: Heavy episodic drinking on alcohol-related problems among Asian Americans. Alcohol 
Research: Current Reviews, 38, 17-25.

Kim, I. J., Zane, N. W. S., \& Hong, S. (2002). Protective factors against substance use among Asian American youth: A test of the peer cluster theory. Journal of Community Psychology, 30, 565-584. doi:10.1002/jcop.10022

Kuitunen-Paul, S., \& Roerecke, M. (2018). Alcohol Use Disorders Identification Test (AUDIT) and mortality risk: A systematic review and meta-analysis. Journal of Epidemiology and Community Health, 72, 856. doi:10.1136/jech-2017-210078

LaBrie, J. W., Kenney, S. R., Napper, L. E., \& Miller, K. (2014). Impulsivity and alcohol-related risk among college students: Examining urgency, sensation seeking and the moderating influence of beliefs about alcohol's role in the college experience. Addictive Behaviors, 39, 159-164. doi:10.1016/j.addbeh.2013.09.018

Lazarus, R. S. (1997). Acculturation isn't everything. Applied Psychology: An International Review, 46, 39-43. doi:10.1111/j.1464-0597.1997.tb01089.x

Levinson, C., \& Rodebaugh, T. (2013). Anxiety, self-discrepancy, and regulatory focus theory: Acculturation matters. Anxiety, Stress \& Coping, 26, 171-186. doi:10.1080/10615806.2012.659728

Lorenzo-Blanco, E. I., Meca, A., Unger, J. B., Romero, A., Gonzales-Backen, M., Piña-Watson, B., . . \& \& Schwartz, S. J. (2016). Latino parent acculturation stress: Longitudinal effects on family functioning and youth emotional and behavioral health. Journal of Family Psychology, 30, 966-976. doi:10.1037/fam0000223

Lui, P. P. (2019). College alcohol beliefs: Measurement invariance, mean differences, and correlations with alcohol use outcomes across sociodemographic groups. Journal of Counseling Psychology. Advance online publication. doi:10.1037/cou0000338 
Lui, P. P. (2015). Intergenerational cultural conflict, mental health, and educational outcomes among Asian and Latino/a Americans: Qualitative and meta-analytic review. Psychological Bulletin, 141, 404-446. doi:10.1037/a0038449

Lui, P. P., \& Zamboanga, B. L. (2018). Acculturation and alcohol use among Asian Americans: A meta-analytic review. Psychology of Addictive Behaviors, 32, 173-186. doi:10.1037/adb0000340

Mallett, K. A., Varvil-Weld, L., Borsari, B., Read, J. P., Neighbors, C., \& White, H. R. (2013). An update of research examining college student alcohol-related consequences: New perspectives and implications for interventions. Alcoholism: Clinical and Experimental Research, 37, 709-716. doi:10.1111/acer.12031

Mulia, N., \& Zemore, S. E. (2012). Social adversity, stress, and alcohol problems: Are racial/ethnic minorities and the poor more vulnerable? Journal of Studies on Alcohol and Drugs, 73, 570-580. doi:10.15288/jsad.2012.73.570

Neighbors, C., LaBrie, J. W., Hummer, J. F., Lewis, M. A., Lee, C. M., Desai, S., ... \& Larimer, M. E. (2010). Group identification as a moderator of the relationship between perceived social norms and alcohol consumption. Psychology of Addictive Behaviors, 24, 522-528. doi:10.1037/a0019944

Osberg, T. M., Atkins, L., Buchholz, L., Shirshova, V., Swiantek, A., Whitley, J., ... \& Oquendo, N. (2010). Development and validation of the College Life Alcohol Salience Scale: A measure of beliefs about the role of alcohol in college life. Psychology of Addictive Behaviors, 24, 1-12. doi:10.1037/a0018197

Osberg, T. M., Insana, M., Eggert, M., \& Billingsley, K. (2011). Incremental validity of college alcohol beliefs in the prediction of freshman drinking and its consequences: A 
prospective study. Addictive Behaviors, 36, 333-340. doi:10.1016/j.addbeh.2010.12.004

Pham, S. \& Lui, P. P. (2019a). Acculturation and alcohol use outcomes: Incremental roles of bicultural orientations among Asian American undergraduate and graduate students. Manuscript submitted for publication.

Pham, S. \& Lui, P. P. (2019b). Acculturation, biculturalism, and alcohol use among Hispanic Americans. Alcoholism: Clinical \& Experimental Research, 43(S1), 60A. doi:10.1111/acer.14056

Putnick, D. L., \& Bornstein, M. H. (2016). Measurement invariance conventions and reporting: The state of the art and future directions for psychological research. Developmental Review, 41, 71-90. doi:10.1016/j.dr.2016.06.004

Reed, M. B., Lange, J. E., Ketchie, J. M., \& Clapp, J. D. (2007). The relationship between social identity, normative information, and college student drinking. Social Influence, 2, 269294. doi:10.1080/15534510701476617

Reinert, D. F. \& Allen, J. P. (2002). The Alcohol Use Disorders Identification Test (AUDIT): A review of recent research. Alcoholism: Clinical and Experimental Research, 26, 272-279. doi:10.1111/j.1530-0277.2002.tb02534.x

SAMHSA (2017). Results from the 2016 National Survey on Drug Use and Health: Detailed tables. Rockville, MD: Substance Abuse and Mental Health Services Administration. Retrieved from http://store.samhsa.gov/home.

Saunders, J. B., Aasland, O. G., Babor, T. F., \& de la Fuente, J. R. (1993). Development of the Alcohol Use Disorders Identification Test (AUDIT): WHO collaborative project on early detection of persons with harmful alcohol consumption--II. Addiction, 88, 791-804.

Savic, M., Room, R., Mugavin, J., Pennay, A., \& Livingston, M. (2016). Defining “drinking 
culture": A critical review of its meaning and connotation in social research on alcohol problems. Drugs: Education, Prevention and Policy, 23, 270-282. doi:10.3109/09687637.2016.1153602

Stephenson, M. (2000). Development and validation of the Stephenson Multigroup Acculturation Scale (SMAS). Psychological Assessment, 12, 77-88. doi:10.1037/1040-3590.12.1.77

Sue, S., Kitano, H. H. L., Hatanaka, H., \& Yeung, W. (1985). Alcohol consumption among Chinese in the United States. In L. A. Bennett \& G. M. Ames (Eds.), The American experience with alcohol: Contrasting cultural perspectives (pp. 359-371). New York: Plenum Press.

Tan, A. S. L. (2012). Through the drinking glass: An analysis of the cultural meanings of college drinking. Journal of Youth Studies, 15, 119-142. doi:10.1080/13676261.2011.630997

Todorova, I., Tucker, K., Jimenez, M., Lincoln, A., Arevalo, S., \& Falcón, L. (2013). Determinants of self-rated health and the role of acculturation: Implications for health inequalities. Ethnicity \& Health, 18, 563-585. doi:10.1080/13557858.2013.771147

Toomey, T. L., \& Wagenaar, A. C. (2002). Environmental policies to reduce college drinking: Options and research findings. Journal of Studies on Alcohol, Supplement, 193-205. doi:10.15288/jsas.2002.s14.193

Vaeth, P. A. C., Wang-Schweig, M., \& Caetano, R. (2017). Drinking, alcohol use disorder, and treatment access and utilization among U.S. racial/ethnic groups. Alcoholism: Clinical and Experimental Research, 41, 6-19. doi:10.1111/acer.13285

Wechsler, H., Dowdall, G. W., Maenner, G., Gledhill-Hoyt, J., \& Lee, H. (1998). Changes in binge drinking and related problems among American college students between 1993 and 1997: Results of the Harvard School of Public Health College Alcohol Study. Journal of 
American College Health, 47, 57-68. doi:10.1080/07448489809595621

Westermeyer, J. (1985). Hmong drinking practices in the United States: The influence of migration. In L. A. Bennett \& G. M. Ames (Eds.), The American experience with alcohol: Contrasting cultural perspectives (pp. 373-391). New York: Plenum Press.

WHO (2016). Total (recorded +unrecorded) alcohol per capita (15+) consumption. World Health Organization. Retrived from http://apps.who.int/gho/data/view.sdg.3-5-datareg?lang=en

Widaman, K. F., \& Reise, S. P. (1997). Exploring the measurement invariance of psychological instruments: Applications in the substance use domain. In K. J. Bryant, M. Windle, \& S. G. West (Eds.), The science of prevention: Methodological advances from alcohol and substance abuse research. (pp. 281-324). Washington, DC: American Psychological Association.

Wilsnack, R. W., Vogeltanz, N. D., Wilsnack, S. C., \& Harris, T. R. (2000). Gender differences in alcohol consumption and adverse drinking consequences: Cross-cultural patterns. Addiction, 95, 251-265. doi:10.1046/j.1360-0443.2000.95225112.x

Wolburg, J., M. . (2001). The "risky business" of binge drinking among college students: Using risk models for psas and anti-drinking campaigns. Journal of Advertising, 30, 23-39.

Zamboanga, B. L., Olthuis, J. V., Kenney, S. R., Correia, C. J., Van Tyne, K., Ham, L. S., \& Borsari, B. (2014). Not just fun and games: A review of college drinking games research from 2004 to 2013. Psychology of Addictive Behaviors, 28, 682-695. doi:10.1037/a0036639

Zamboanga, B. L., Tomaso, C. C., \& Lui, P. P. (2017). Acculturation and alcohol use among Hispanic and Asian American college students: What do we know and where could we 
go? In S. J. Schwartz \& J. B. Unger (Eds.), The Oxford handbook of acculturation and health (pp. 263-280). Oxford: Oxford University Press. 
Table 1

Correlations among Key Variables for Asian American $(N=257)$ and Euro American $(N=117)$ Drinkers

\begin{tabular}{|c|c|c|c|c|c|c|c|c|c|}
\hline & $M$ & $S D)$ & Hedges' & $t(d f)$ & 1. & 2. & 3. & 4. & 5. \\
\hline & $\frac{\text { Asian }}{\text { American }}$ & $\frac{\text { Euro }}{\text { American }}$ & & & & & & & \\
\hline 1. College Alcohol Beliefs & $2.60(0.72)$ & $3.18(0.79)$ & 0.78 & $7.00(365)^{* *}$ & -- & 0.04 & -0.11 & $0.60 * * *$ & $0.44 * * *$ \\
\hline 2. U.S. Cultural Orientation & $3.40(0.54)$ & $3.88(0.17)$ & 1.05 & $6.90(309) * *$ & 0.00 & -- & 0.11 & -0.14 & -0.01 \\
\hline 3. Heritage Cultural Orientation & $2.75(0.81)$ & $2.77(1.05)$ & 0.02 & $0.22(309)$ & $-0.21 * * *$ & $-0.26 * * *$ & -- & 0.01 & 0.04 \\
\hline 4. Typical Alcohol Consumption & $3.28(2.17)$ & $6.45(2.71)$ & 1.35 & $12.09(372)^{* *}$ & $0.38 * * *$ & $0.17 *$ & $-0.20 * *$ & -- & $0.57 * * *$ \\
\hline 5. Alcohol-Related Problems & $2.39(3.39)$ & $4.74(3.96)$ & 0.66 & $5.89(372)^{* *}$ & $0.32 * * *$ & $-0.24 * * *$ & -0.11 & $0.42 * * *$ & -- \\
\hline
\end{tabular}

Note. Correlations for Asian Americans are listed below the diagonal, and the correlations for Euro Americans are listed above the diagonal. Correlations in bold indicate effect sizes that are statistically significantly different between Asian and Euro Americans. $* p<.05, * * p<.005, * * * p<.001$ 
Table 2

Logistic Regression Predicting Drinker Status by Ethnicity, College Alcohol Beliefs, Cultural Orientations, and Interactions (N= 432)

\begin{tabular}{|c|c|c|c|c|c|c|}
\hline \multirow[b]{2}{*}{ Predictor } & \multicolumn{3}{|c|}{ Model 1} & \multicolumn{3}{|c|}{ Model 2} \\
\hline & $B(S E)$ & Wald $\chi^{2}$ & $\operatorname{Exp}(B)$ & $B(S E)$ & Wald $\chi^{2}$ & $\operatorname{Exp}(B)$ \\
\hline Gender $($ Man $=0)$ & $-0.02(0.27)$ & 0.01 & 0.98 & $-0.04(0.28)$ & 0.02 & 0.96 \\
\hline Ethnicity $($ Euro American $=0)$ & $1.59(2.01)$ & 0.62 & 4.90 & $2.17(2.30)$ & 0.90 & 8.80 \\
\hline College Alcohol Beliefs & $5.08(2.18)$ & 5.44 & $160.67 *$ & $-0.95(5.98)$ & 0.03 & 0.39 \\
\hline U.S. Cultural Orientation & $0.72(0.82)$ & 0.77 & 2.06 & $0.73(0.82)$ & 0.79 & 2.07 \\
\hline Heritage Cultural Orientation & $1.30(0.70)$ & 3.49 & 3.66 & $1.31(0.71)$ & 3.42 & 3.70 \\
\hline College Alcohol Beliefs x Ethnicity & $-1.31(1.15)$ & 1.31 & 0.27 & $4.76(5.75)$ & 0.69 & 116.26 \\
\hline College Alcohol Beliefs x U.S. Cultural Orientation & $0.08(.036)$ & 0.05 & 1.08 & $1.77(1.74)$ & 1.04 & 5.89 \\
\hline College Alcohol Beliefs x Heritage Cultural Orientation & $-0.77(0.33)$ & 5.30 & $0.46^{*}$ & $-0.82(0.69)$ & 1.40 & 0.44 \\
\hline College Alcohol Beliefs x U.S. Cultural Orientation x Ethnicity & & & & $-1.70(1.72)$ & 0.98 & 0.18 \\
\hline College Alcohol Beliefs x Heritage Cultural Orientation x Ethnicity & & & & $0.04(0.57)$ & 0.01 & 1.04 \\
\hline Model $\chi^{2}(d f)$ & $146.13 * *(8)$ & & & $147.04 * *(10)$ & & \\
\hline
\end{tabular}

Note. Gender was included as a covariate in all models.

$* p<.05, * * p<.001$ 
Table 3

Poisson Regression Predicting Alcohol Consumption by Ethnicity, College Alcohol Beliefs, Cultural Orientations, and Interactions (N $=310)$

\begin{tabular}{|c|c|c|c|c|c|c|}
\hline \multirow[b]{2}{*}{ Predictor } & \multicolumn{3}{|c|}{ Model 1} & \multicolumn{3}{|c|}{ Model 2} \\
\hline & $B(S E)$ & Wald $\chi^{2}$ & $\operatorname{Exp}(B)$ & $B(S E)$ & Wald $\chi^{2}$ & $\operatorname{Exp}(B)$ \\
\hline Ethnicity (Euro American $=0$ ) & $-0.76(0.28)$ & 7.26 & $0.47 *$ & $-0.75(0.28)$ & 7.26 & $0.47^{*}$ \\
\hline U.S. Cultural Orientation & $-0.29(0.28)$ & 1.03 & 0.75 & $-0.38(0.29)$ & 1.72 & 0.69 \\
\hline Heritage Cultural Orientation & $-0.35(0.13)$ & 7.03 & $0.71 *$ & $-0.28(0.14)$ & 3.95 & $0.76^{*}$ \\
\hline College Alcohol Beliefs x Ethnicity & $0.10(0.09)$ & 1.46 & 1.11 & $-0.38(0.34)$ & 1.24 & 0.69 \\
\hline College Alcohol Beliefs x U.S. Cultural Orientation x Ethnicity & & & & $0.14(0.08)$ & 2.88 & 1.15 \\
\hline College Alcohol Beliefs x Heritage Cultural Orientation x Ethnicity & & & & $-0.03(0.02)$ & 1.60 & 0.97 \\
\hline Model $\chi^{2}(d f)$ & $259.41 * *(8)$ & & & $263.95 * *(10)$ & & \\
\hline
\end{tabular}

Note. Only individuals who reported consuming alcohol in the past six months were included in the analyses. Gender was included as a covariate in all models.

$* p<.05, * * p<.001$ 
Table 4

Negative Binomial Regression Predicting Alcohol-Related Problems by Ethnicity, College Alcohol Beliefs, Cultural Orientations, and Interactions $(N=310)$

\begin{tabular}{|c|c|c|c|c|c|c|}
\hline \multirow[b]{2}{*}{ Predictor } & \multicolumn{3}{|c|}{ Model 1} & \multicolumn{3}{|c|}{ Model 2} \\
\hline & $B(S E)$ & Wald $\chi^{2}$ & $\operatorname{Exp}(B)$ & $B(S E)$ & Wald $\chi^{2}$ & $\operatorname{Exp}(B)$ \\
\hline Ethnicity (Euro American $=0$ ) & $-1.62(0.93)$ & 3.06 & 0.20 & $-1.55(0.93)$ & 2.79 & 0.21 \\
\hline U.S. Cultural Orientation & $-1.55(0.72)$ & 4.72 & $0.21 *$ & $-1.50(0.72)$ & 4.36 & $0.22 *$ \\
\hline Heritage Cultural Orientation & $-0.89(0.39)$ & 5.31 & $0.41 *$ & $-0.77(0.42)$ & 3.36 & 0.46 \\
\hline College Alcohol Beliefs x Ethnicity & $0.38(0.29)$ & 1.73 & 1.47 & $0.74(1.16)$ & 0.41 & 2.09 \\
\hline College Alcohol Beliefs x U.S. Cultural Orientation x Ethnicity & & & & $-0.06(0.28)$ & 0.06 & 0.94 \\
\hline College Alcohol Beliefs x Heritage Cultural Orientation x Ethnicity & & & & $-0.05(0.07)$ & 0.60 & 0.95 \\
\hline Model $\chi^{2}(d f)$ & $87.29 * *(8)$ & & & $87.94 * *(10)$ & & \\
\hline
\end{tabular}

Note. Only individuals who reported consuming alcohol in the past six months were included in the analyses. Gender was included as a covariate in all models.

$* p<.05 * * p<.001$ 


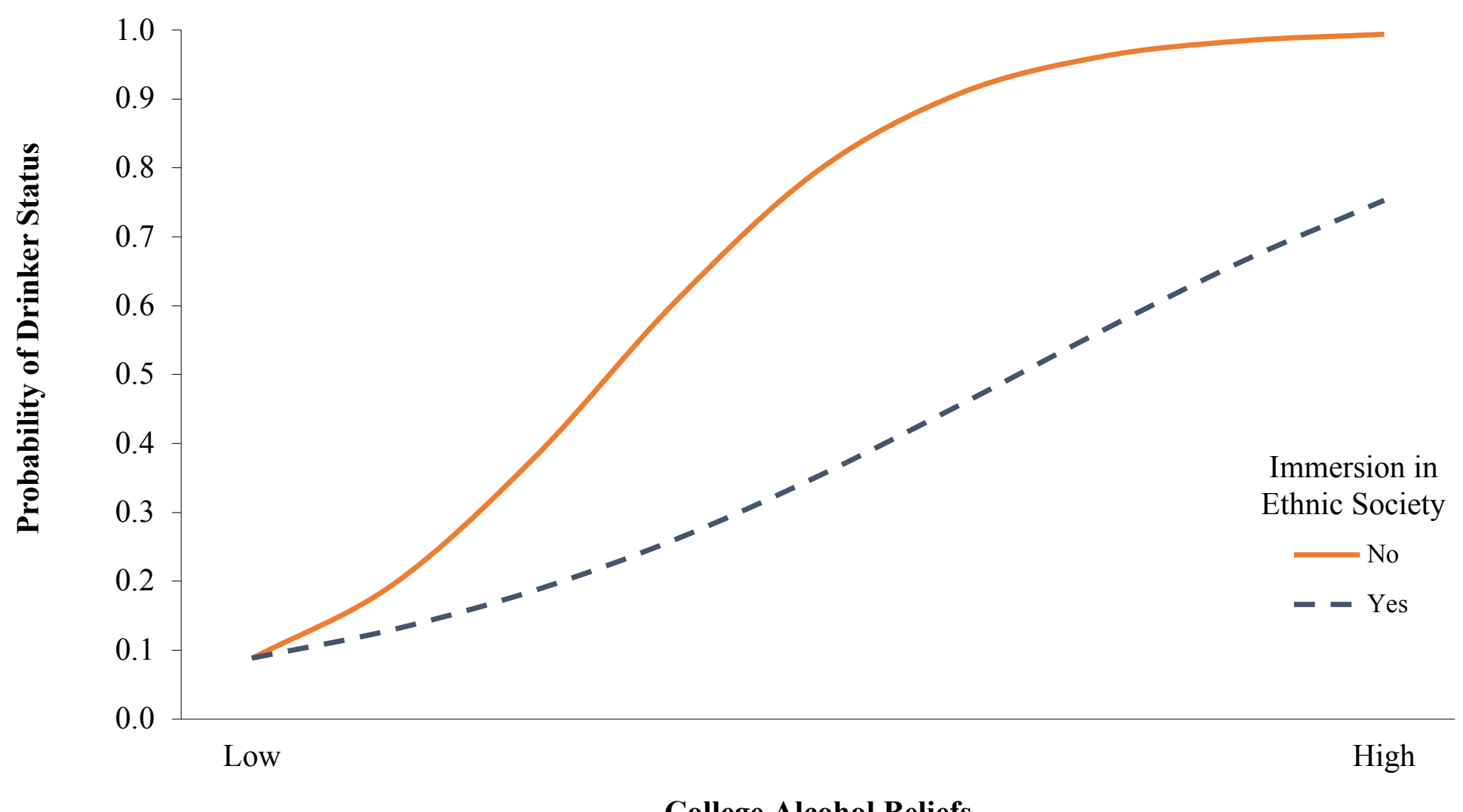

Figure 1. Graphical illustration of the moderating role of heritage cultural orientation on the association between college alcohol beliefs and probability of being a drinker. Logistic regression model 1 (see Table 2) also included gender, ethnicity, and U.S. cultural orientation. Low and high levels of college alcohol beliefs range from 1 (strongly disagree) to 5 (strongly agree) on the College Life Alcohol Salience Scale, and heritage cultural orientation is plotted at values of 1 (not immersed in ethnic society) and 4 (immersed in ethnic society) of the Stephenson Multigroup Acculturation Scale. 


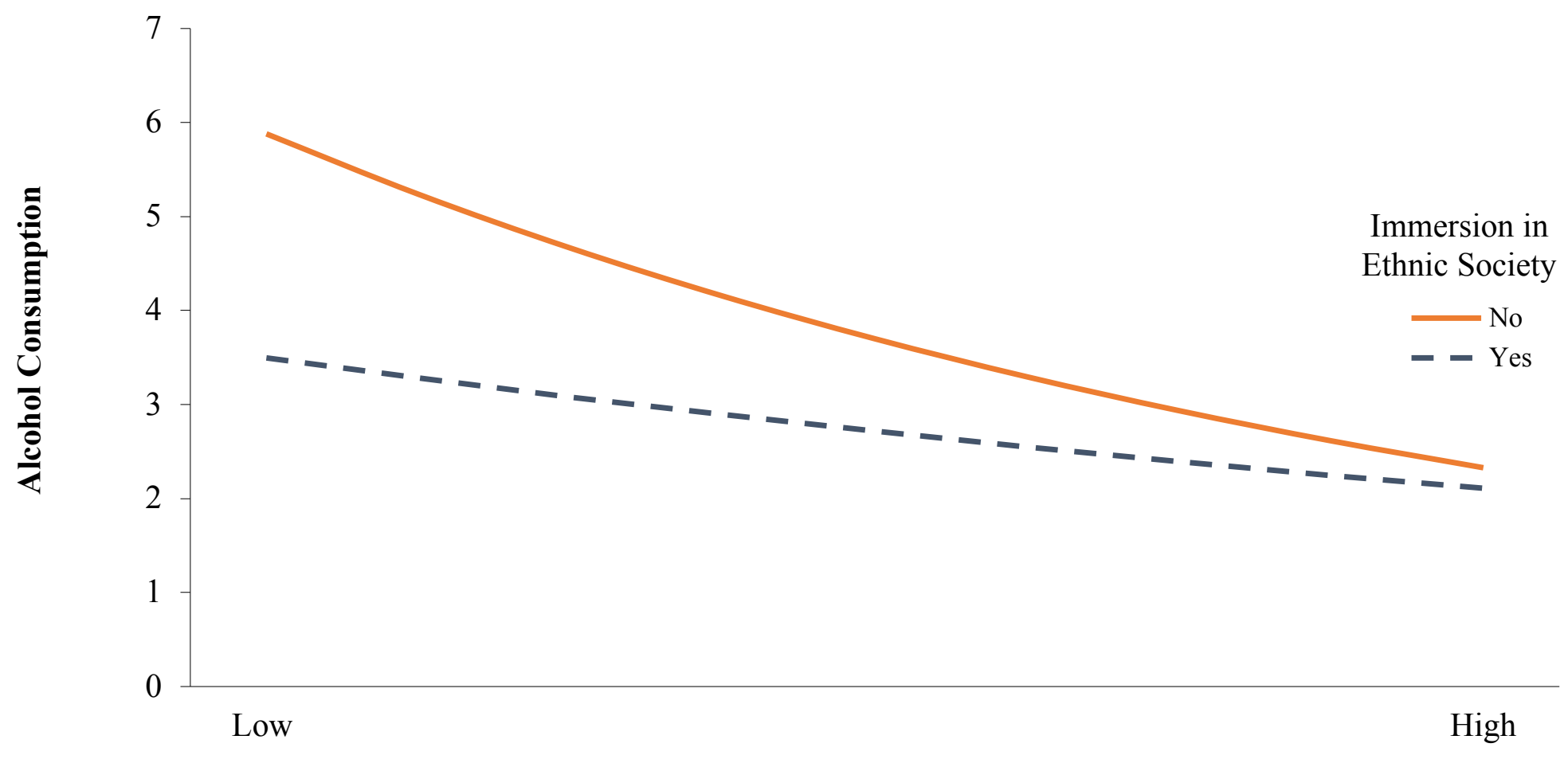

\section{College Alcohol Beliefs}

Figure 2. Graphical illustration of the moderating role of heritage cultural orientation on the association between college alcohol beliefs and alcohol consumption among individuals who drank in the past six months. Poisson regression models 1 and 2 (see Table 3 ) also included gender, ethnicity, and U.S. cultural orientation. Low and high levels of college alcohol beliefs range from 1 (strongly disagree) to 5 (strongly agree) on the College Life Alcohol Salience Scale, and heritage cultural orientation is plotted at values of 1 (not immersed in ethnic society) and 4 (immersed in ethnic society) of the Stephenson Multigroup Acculturation Scale. 


\begin{abstract}
Appendix
Invariant Items in Modified College Life Alcohol Salience Scale and Modified Stephenson Multigroup Acculturation Scale across Asian and Euro Americans
\end{abstract}

Modified College Life Alcohol Salience Scale (14 Items)

1. Parties with alcohol are an integral part of college life.

2. To become drunk is a college rite of passage.

3. The reward at the end of a hard week of studying should be a weekend of heavy drinking.

4. I think that the students who do not go out to parties or bars are not enjoying their college experience.

5. Missing class due to a hangover is part of being a true college student.

6. A college party is not a true college party without alcohol.

7. Alcohol is not an important aspect of college life.

8. Attending parties in college is the easiest way to make friends.

9. Drinking alcohol is a social event in which every college student partakes.

10. College is a time for experimentation with alcohol.

11. A good college party should include drinking games such as beer pong, flip cup, power hour, etc.

12. Blacking out or forgetting part or all of the previous night's events is to be expected in college.

13. It is okay to drink in college, even if you are under age.

14. The chance to drink and party in college is just as important as the academic experience.

Modified Stephenson Multigroup Acculturation Scale (26 Items)

1. I am informed about current affairs in the United States. (DSI)

2. I speak my native language with my friends and acquaintances from

3. I have never learned to speak the language of . (ESI)

4. I feel totally comfortable with Anglo American people. (DSI)

5. I have many Anglo American acquaintances. (DSI)

6. I feel comfortable speaking my native language. (ESI)

7. I am informed about current affairs in (ESI)

8. I know how to read and write in my native language. (ESI)

9. I feel at home in the United States. (DSI)

10. I attend social functions with people from (ESI)

11. I speak my native language at home. (ESI)

12. I regularly read magazines of my ethnic group. (ESI)

13. I know how to speak my native language. (ESI)

14. I know how to prepare Anglo American foods. (ESI)

15. I like to listen to music of my ethnic group. (ESI)

16. I like to speak my native language. (ESI)

17. I feel comfortable speaking English. (DSI)

18. I speak English at home. (DSI)

19. I speak my native language with my spouse or partner. (ESI)

20. When I pray, I use my native language. (ESI)

21. I attend social functions with Anglo American people. (DSI)

22. I think in my native language. (ESI)

23. I stay in close contact with family members and relatives in

24. I am familiar with important people in American history. (DSI) . (ESI)

25. I speak English with my spouse or partner. (DSI)

26. I like to eat American foods. (DSI)

Note. Insert the blanks with "country of origin" or "native country" for items that refer to the country from which your family originally came, and "native language" for items that refer to the language spoken where your family originally came. DSI = dominant society immersion and ESI = ethnic society immersion. 